\title{
Insider Power and Average Labor Demand When Recessions Are Prolonged
}

\author{
Pilar Díaz-Vázquez \\ Departamento de Fundamentos del Análisis Económico, Facultad de Ciencias Económicas y Empresariales, Universidad de Santiago \\ de Compostela, Avenida do Burgo S/N, A Coruña 15784 Santiago de Compostela, Spain
}

Correspondence should be addressed to Pilar Díaz-Vázquez; p.diaz@usc.es

Received 25 September 2013; Accepted 11 October 2013

Academic Editor: Colin C. Williams

Copyright (C) 2013 Pilar Díaz-Vázquez. This is an open access article distributed under the Creative Commons Attribution License, which permits unrestricted use, distribution, and reproduction in any medium, provided the original work is properly cited.

This paper examines how insider power in wage negotiations affects average labor demand when recessions are more persistent than booms. It shows that the effect of insider power on average labor demand is more contractionary the greater is the persistence of troughs relative to booms. This analysis is a contribution to the discussion of why the existence of dual labor markets (in which insider power is strong) is negative for employment in the current situation of more prolonged troughs.

\section{Introduction}

The existence of dual labor markets has been pointed out as one of the main problems of some European countries with high unemployment levels. The dual labor market is defined as the division of the workforce into "insiders" and "outsiders," where insiders are incumbent workers that enjoy protected jobs, so that they receive severance payments in case of dismissal and that can use this power in wage negotiation, while outsiders are both temporary workers and unemployed people (see Lindbeck and Snower [1] for the seminal contribution to this literature). Some authors consider that this kind of divide is especially negative for employment when the economy is suffering a recession (see Bentolila et al. [2, 3]).

This paper contributes to the discussion of why the insider/outsider divide is more harmful for employment when recessions are prolonged. In particular, it focuses on the power of insiders to obtain higher wages and on how this affects average labor demand.

For this purpose, I use a model in a dynamic stochastic framework with recessions and recoveries. If the economy is in a boom, firms may be experiencing an increase in the demand for its product, so they have an incentive to hire new workers. In the model, new workers (called "entrants") have no employment protection (i.e., they are not permanent workers) and, after a given period, they may either be fired or transformed into insiders. (I use the term "entrants" as appears in Lindbeck and Snower [1].) When the firm hires the "entrants," these newly recruited workers receive their reservation wage, that is, the wage at which the present value of their expected utility is equal to the present value of an unemployed person's expected utility. This implies that a future expected higher insider wage may be compensated for in the current entrant wage. Some authors consider that this behavior makes insider power in wage determination neutral for employment (see, e.g., Bertola [4], Fehr and Kirchsteiger [5], Frank and Malcomson [6], Gottfries and Sjöström [7], and Lazear [8]).

It is true that firms usually have a much stronger influence over wages than workers who are just hired, and that it is difficult to stop firms from driving entrant wages down, so this entrant wage may reach the reservation wage. This may imply that the reservation wage is a reasonable approximation of entrant wages (although there are some rationales for discrepancies between the entrant wage and the reservation wage) (see Lindbeck and Snower [9] for a survey of these reasons).

Under the assumption that entrats receive the reservation wage, it is correct to think that new hirings may not be affected by the higher insider wage. However, Díaz-Vázquez and Snower [10] show that also the firing decision must be considered (see also Díaz-Vázquez and Snower [11]). Employment in a recession (when the firm is firing workers) 
will be lower the higher is the insider wage, but also the lower is the entrant wage. If entrants are more profitable relative to insiders, the firms will have an incentive to fire more insiders in a recession: it is better for the firm to fire the insiders in the recession (that receive a high wage) and replace them with cheaper entrants in the next recovery.

This paper focuses on the role of the persistence of the shocks in this context. In a stochastic model where firms experience booms and recession and where the persistence of good and bad shocks is asymmetric, I analyse how the greater persistence of recessions affects the influence of insider power on employment. The model also takes into account that severance payments are usually proportional to the insider wage, so a higher insider wage also increases severance payments.

In this context, the paper shows that the more prolonged are recessions relative to booms, the greater is the contractionary effect of insider power on employment. This is so because the greater insider wage promotes firing in a recession, while leaving hiring in a boom unchanged. Since the higher insider wage affects employment mainly in recession, the greater proportion of recessions makes insider power more contractionary for employment. (There are some papers that study the interaction of the business cycles and permanent and temporary workers (see Costain et al. [12]). However, they study the volatility of employment when there is a single contract, but they do not focus on the interaction between insider power and the duration of the shocks.)

The model also takes into account that severance payments are usually proportional to the insider wage: a higher insider wage has the side effect of increasing severance payments, which in turn discourages firing. The greater is the proportion of recessions relative to booms, the more it increases employment (see also Díaz-Vázquez and ArjonaBéjar [13] and Díaz-Vázquez, Snower, and Arjona-Béjar [14]). However, the direct influence of the insider wage on labor demand is the one that dominates, since severance payments are only a proportion of the annual insider wage.

In this context of asymmetric economic fluctuations, I also show that the results above may hold for different production functions.

The paper is organized as follows. Section 2 presents the model. Section 3 analyzes the influence of insider power on employment in the short run, whereas Section 4 analyzes the influence of insider power on employment in the long run. Section 5 presents the conclusions.

\section{The Model}

Consider an economy with a number of identical firms. (For simplicity, perfect competition in the product market is assumed; i.e., each firm is a price taker.) Each firm has a revenue function equal to $R_{\tau}(L, Z)=Z_{\tau} L_{\tau}-(c / 2) L_{\tau}^{2}$, where $L_{\tau}$ is the firm's employment, $c$ is a positive constant, and $Z_{\tau}$ is a random variable that represents economic conditions. (To analyze long-run labor demand, we need to refer to a specific revenue function. The function used is the simplest case, since the demand for labor is linear with additive shocks (i.e., the reaction of employment to a change in the marginal revenue is the same for any state of nature). I can show that the results below also hold for other revenue functions, in particular for a revenue function linear quadratic in labor with multiplicative shocks and a Cobb-Douglas revenue function (see appendix).) $Z_{\tau}$ follows a two-state Markov chain: the economy is in a "good state" when $Z_{\tau}=Z^{G}$ and it is in a "bad state" when $Z_{\tau}=Z^{B}$, where $Z^{G}>Z^{B}$. The matrix of Markov transition probabilities is $\left(\begin{array}{cc}P^{G} & 1-P^{G} \\ 1-P^{B} & P^{B}\end{array}\right)$, where $P^{G}$ is the probability that the economy remains in the good state and $P^{B}$ is the probability of remaining in the bad state. In this context, the probabilities $P^{G}$ and $P^{B}$ measure the persistence of a good state (i.e., the persistence of a boom) and the persistence of a bad state (i.e., the persistence of a trough). When the firm makes its employment decision in period $t$, it knows $Z_{t}^{i}$, that is, current business conditions. Regarding the future values of $Z_{\tau}$, the firm knows the Markov matrix, and thus it has rational expectations about $Z_{\tau}$.

I assume that the fluctuations of $Z_{\tau}$ are of sufficient magnitude so that in a recovery (when the economy moves from a bad state to a good state), the firm hires new workers, and in a downturn (when the economy moves from a good state to a bad state), the firm fires some workers. When economic conditions do not change, the firm just retains its existing insiders. (We assume that the parameter values of our model are such that we can exclude trivial and irrelevant cases. It is also important to note that our qualitative results do not depend on the Markov structure, see Díaz-Vázquez and Snower [10].)

This paper focuses on how labor demand responds to wages, and, as usual, wages are predetermined when the firm makes its employment decision. In this context, it is not necessary to specify precisely how insider wages are set, so I consider that insider wages are exogenously given: $W^{G}$ in a boom and $W^{B}$ in a recession (upper case variables refer to insiders). (It can be shown that when insider wages are the outcome of a Nash bargaining process, the qualitative results of the paper do not change, see Díaz-Vázquez and ArjonaBéjar [13] for the derivation of the insider wage.)

New workers in the firm are "entrants" during the first period (the hiring cost is $h$ ). If the firm decides to fire them after this first period, it can do it costlessly; that is, entrants receive no severance payments. Only if they remain in the firm during the second period, they become insiders, and thus, if fired, they receive severance payments $F$. This implies that they have no bargaining power in the wage negotiation of the first period, so the entrant wage is equal to the reservation wage $r_{t}$, that is, the wage at which the present value of expected utility from employment $y_{t}^{G}$ is equal to the present value of expected utility from unemployment $\chi_{t}^{G}$ :

$$
y_{t}^{G}=\chi_{t}^{G}
$$

For simplicity, utility is measured by income. Recall that the firm only hires entrants in upturns, so the entrant wage is only relevant in that state. I also assume a seniority rule for firing, 
so that entrants hired today are the first workers fired in the next downturn. Thus $y_{t}^{G}$ is as follows ( $\delta$ is the discount factor):

$y_{t}^{G}=r_{t}+\frac{\delta P^{G}}{1-\delta P^{G}}\left[W^{G}+\delta\left(1-P^{G}\right) \chi_{t+2}^{B}\right]+\delta\left(1-P^{G}\right) \chi_{t+1}^{B}$,

where $\chi_{t+i}^{B}$ is the present value of an unemployed person income in a recession (that occurs with probability $1-P^{G}$ ).

Since the Markov process is stationary, then $\chi_{t}^{B}=\chi_{t+j}^{B}$ and $\chi_{t}^{G}=\chi_{t+j}^{G}$ for any $j$, so the temporal subscript can be ignored. Let $b$ be the unemployment benefit (a positive constant). It can be shown that

$$
\chi^{G}=\chi^{B}=\frac{b}{1-\delta}
$$

that is, the present value of expected utility when the worker is unemployed equals the present value of the unemployment benefit $b$ over the future (since $y_{t}^{G}=\chi^{G}$, then $\chi^{G}=b+\delta P^{G} \chi^{G}+$ $\delta\left(1-P^{G}\right) \chi^{B}$ and $\chi^{B}=b+\delta P^{B} \chi^{B}+\delta\left(1-P^{B}\right) \chi^{G}$. Solving, we obtain (3)).

From (1), (2), and (3), the expression for the entrant (reservation) wage in a boom $r$ is

$$
r=b-\frac{\delta P^{G}}{1-\delta P^{G}}\left(W^{G}-b\right)
$$

that is, $r$ is equal to the unemployment benefit $b$ minus the expected future differential between the income of an insider $W^{G}$ and that of an unemployed worker $b$.

In this model all workers are equally productive, so that employment is $L=n+N$, where $n$ is the number of entrants and $N$ is the number of insiders.

Since the paper focuses on the effect of insider wages on labor demand, it also considers the influence of wages on the cost of dismissal. Since I assume that firing costs $F$ only include severance payments, $F$ are proportional to insider wages $F=\gamma \widehat{W}$, where $\widehat{W}$ is the annual wage used to calculate severance payments (that depends on $W^{G}$ and $W^{B}$ ) and $\gamma$ is a positive constant.

2.1. The Hiring and Firing Decisions. The firm decides on the level of employment that maximizes the present value of its profit. In an upturn, the firm hires new workers, and its maximization problem is

$$
\begin{gathered}
\max _{n_{t}}\left[Z^{G}\left(n_{t}^{G}+N_{t}^{G}\right)-\frac{c}{2}\left(n_{t}^{G}+N_{t}^{G}\right)^{2}\right] \\
-r n_{t}^{G}-W^{G} N_{t}^{G}-h n_{t}^{G}+\delta E \Omega_{t+1},
\end{gathered}
$$

where $\left[Z^{G}\left(n_{t}^{G}+N_{t}^{G}\right)-(c / 2)\left(n_{t}^{G}+N_{t}^{G}\right)^{2}\right]$ is the revenue, $r n_{t}^{G}+$ $W^{G} N_{t}^{G}+h n_{t}^{G}$ are the labor costs, and $E \Omega_{t+1}$ is expected future profit.

The first-order condition is

$$
\left[Z^{G}-c\left(n_{t}^{G}+N_{t}^{G}\right)\right]-r-h+\delta P^{G}\left(\Omega_{t+1}^{G}\right)^{\prime}=0
$$

that is, the present value of the entrant expected marginal profitability is zero. In (6), $\left[Z^{G}-b\left(n_{t}^{G}+N_{t}^{G}\right)\right]-r-h$ is the profit in the current period. Recall that, due to the seniority rule for firing, the marginal entrant will be fired in a recession, and he receives no severance payments, so, if there is a recession in period $t+1$, the expected marginal profitability is zero. With probability $P^{G}$, the boom continues in period $t+1$, the entrants become insiders, and thus the firm obtains $\left(\Omega_{t+1}^{G}\right)^{\prime}$, which is the present value of expected profit of an insider:

$$
\begin{aligned}
\left(\Omega_{t+1}^{G}\right)^{\prime}=\frac{1}{1-\delta P^{G}}\{ & {\left[Z^{G}-c\left(n_{t}^{G}+N_{t}^{G}\right)\right] } \\
& \left.-W^{G}-\delta\left(1-P^{G}\right) F\right\} .
\end{aligned}
$$

Observe that, with probability $\left(1-P^{G}\right)$, there is a recession in $t+2$ and the marginal insider is fired, so the firm has to pay a severance payment $F$. Substituting (4) and (7) into (6), the marginal hiring condition becomes

$$
\begin{aligned}
& {\left[Z^{G}-c\left(n_{t}^{G}+N_{t}^{G}\right)\right]-b-h} \\
& \quad+\delta P^{G}\left[h-\delta\left(1-P^{G}\right) F\right]=0 .
\end{aligned}
$$

Thus, boom-time employment $L^{G}=n_{t}^{G}+N_{t}^{G}$ is

$$
L^{G}=\frac{1}{c}\left\{Z^{G}-b-h+\delta P^{G}\left[h-\delta\left(1-P^{G}\right) F\right]\right\} .
$$

In a downturn, the firm fires some workers, and its firing decision problem is

$$
\begin{gathered}
\max _{N_{t}^{B}}\left[Z^{B}\left(N_{t}^{B}\right)-\frac{c}{2}\left(N_{t}^{B}\right)^{2}\right]-W^{B} N_{t}^{B} \\
-F\left(N_{t-1}^{G}-N_{t}^{B}\right)+\delta E \Omega_{t+1} .
\end{gathered}
$$

The first-order condition is

$$
\begin{aligned}
& {\left[Z^{B}-c\left(N_{t}^{B}\right)\right]-W^{B}-\delta P^{B} F} \\
& \quad+\delta\left(1-P^{B}\right)\left(\Omega_{t+1}^{G}\right)^{\prime}=-F
\end{aligned}
$$

that is, the present value of the marginal insider's expected profitability is equal to the firing cost $F$. In (11), $\left[Z^{B}-c\left(N_{t}^{B}\right)\right]-$ $W^{B}$ is the profit that the insider generates in $t$. In period $t+1$, the marginal profit will be $-F$ if the recession continues (with probability $P^{B}$ ). If a boom occurs (with probability $1-P^{B}$ ), the marginal profit will be $\left(\Omega_{t+1}^{G}\right)^{\prime}$.

Substituting the marginal insiders profitability (7) and the reservation wage (4) into (11), the marginal firing condition becomes

$$
\begin{aligned}
&-F=\left[Z^{B}-c\left(N_{t}^{B}\right)\right]- W^{B}-\delta P^{B} F \\
&+\delta\left(1-P^{B}\right)\left[h-\frac{1}{1-\delta P^{G}}\left(W^{G}-b\right)\right. \\
&\left.-\delta\left(1-P^{G}\right) F\right] .
\end{aligned}
$$


Thus, recession-time employment $L^{B}=N_{t}^{B}$ is

$$
\begin{aligned}
L^{B}=\frac{1}{c}\left\{Z^{B}+F-W^{B}-\delta P^{B} F\right. & \\
+\delta\left(1-P^{B}\right) & {\left[h-\frac{1}{1-\delta P^{G}}\left(W^{G}-b\right)\right.} \\
& \left.\left.-\delta\left(1-P^{G}\right) F\right]\right\} .
\end{aligned}
$$

With these labor demand functions derived in the stochastic dynamic setting above, the next section investigates the effect of insider power on long-run employment and how it depends on the persistence of recessions.

\section{The Effect of Insider Power on Employment and the Persistence of Recessions}

The effect of higher insider wages on long-run employment $E(L)$ is

$$
\frac{\partial E(L)}{\partial W}=\left.\frac{\partial E(L)}{\partial W}\right|_{\bar{F}}+\frac{\partial E(L)}{\partial F} \frac{\partial F}{\partial W}
$$

where $\partial W=\partial W^{G}=\partial W^{B}$. That is, higher insider wages have (a) a direct effect on employment $\left.(\partial E(L) / \partial W)\right|_{\bar{F}}($ for given $F)$ and (b) an indirect effect via severance payments $(\partial E(L) /$ $\partial F)(\partial F / \partial W)$.

(a) Regarding the direct effect, it equals

$$
\left.\frac{\partial E(L)}{\partial W}\right|_{\bar{F}}=\left.\Pi^{G} \frac{\partial L^{G}}{\partial W}\right|_{\bar{F}}+\left.\Pi^{B} \frac{\partial L^{B}}{\partial W}\right|_{\bar{F}}
$$

where $\Pi^{G}$ is the long-run Markov probability for a good state and $\Pi^{B}$ is the corresponding long-run probability for a bad state. (The long-run Markov probabilities for a good and a bad state are $\Pi^{G}=\left(1-P^{B}\right) /\left[\left(1-P^{G}\right)+\left(1-P^{B}\right)\right]$ and $\Pi^{B}=$ $\left(1-P^{G}\right) /\left[\left(1-P^{G}\right)+\left(1-P^{B}\right)\right]$.) From (9), it can be shown that the insider wage has no influence on employment in a boom:

$$
\left.\frac{\partial L^{G}}{\partial W}\right|_{\bar{F}}=0
$$

This is so because the entrant is receiving the reservation wage, and thus the current entrant wage is lower to compensate for the future expected higher insider wage.

In the recession, however, insider wages have a negative effect on employment:

$$
\left.\frac{\partial L^{B}}{\partial W}\right|_{\bar{F}}=-\frac{1}{c} \Pi^{B}\left[1+\frac{\delta\left(1-P^{B}\right)}{1-\delta P^{G}}\right]<0 .
$$

In the recession, not only the higher insider wage reduces current employment (the insider is the marginal worker), but also the lower entrant wage expected in a future recovery (that occurs with probability $1-P^{B}$ ) encourages firing today. The more persistent are recessions relative to booms (the greater is $P^{B}$ relative to $P^{G}$ ), the greater is the proportion of recessions, and the more contractionary is the effect of insider power on average employment (this effect depends on the discount factor. I can show that the greater the $\delta$ is, the smaller this effect becomes):

$$
\begin{aligned}
& \left.\frac{\partial^{2} E(L)}{\partial W \partial P^{B}}\right|_{\bar{F}} \\
& =-\frac{1}{c}\left\{\frac{\partial \Pi^{B}}{\partial P^{B}}\left[1+\frac{\delta\left(1-P^{B}\right)}{1-\delta P^{G}}\right]-\Pi^{B} \frac{\delta}{1-\delta P^{G}}\right\}<0 .
\end{aligned}
$$

(b) Regarding the indirect effect via severance payments $(\partial E(L) / \partial F)(\partial F / \partial W)$, its sign depends on the sign of $\partial E(L) / \partial F$. It can be shown that higher severance payments $F$ increase average employment (see Díaz-Vázquez and ArjonaBéjar [13]):

$$
\begin{aligned}
\frac{\partial E(L)}{\partial F} \frac{\partial F}{\partial W}= & -\frac{1}{c} \Pi^{G}\left\{\delta^{2} P^{G}\left(1-P^{G}\right) \frac{\partial F}{\partial W}\right\} \\
+ & \frac{1}{c} \Pi^{B}\left\{\left[\left(1-\delta P^{B}\right)\right.\right. \\
& \left.\left.\quad-\delta^{2}\left(1-P^{B}\right)\left(1-P^{G}\right)\right] \frac{\partial F}{\partial W}\right\} \\
= & \frac{1}{c} \frac{\partial F}{\partial W} \Pi^{B}\left\{(1-\delta)\left[1+\delta\left(1-P^{B}\right)\right]\right\}>0 .
\end{aligned}
$$

The reason why $\partial E(L) / \partial F>0$ is that higher severance payments mainly discourage firing (by more than they discourage hiring). (It can be shown that firing costs do not affect the insider wage in a recession, when the firm is firing, see Díaz-Vázquez and Arjona-Béjar [13].) Thus, a higher insider wage increases severance payments, which in turn increases employment. The more persistent are recessions relative to booms and the more important is this positive effect of insider power on employment:

$$
\frac{\partial^{2} E(L)}{\partial F \partial P^{B}} \frac{\partial F}{\partial W}=\frac{1}{c} \frac{\partial F}{\partial W}(1-\delta)\left\{\frac{\partial \Pi^{B}}{\partial P^{B}}\left[1-\delta\left(1-P^{G}\right)\right]\right\}>0 .
$$

Of these two effects (a) and (b), the direct effect of insider power on employment (a) is the one that dominates: substituting (15) and (19) into (14), we can see that

$$
\begin{aligned}
\frac{\partial E(L)}{\partial W}= & -\frac{1}{c} \Pi^{B}\left[1+\frac{\delta\left(1-P^{B}\right)}{1-\delta P^{G}}\right] \\
& +\frac{1}{c} \frac{\partial F}{\partial W} \Pi^{B}\left\{(1-\delta)\left[1+\delta\left(1-P^{B}\right)\right]\right\}<0
\end{aligned}
$$

that is, a higher insider wage reduces average employment, for realistic values of the parameters. (Considering $\delta=0.9$, observe that the lowest value for the "negative term" $[1+$ $\left.\delta\left(1-P^{B}\right) /\left(1-\delta P^{G}\right)\right]$ is 1 , while the highest value for the "positive term" $(\partial F / \partial W)(1-\delta)\left[1+\delta\left(1-P^{B}\right)\right]$ is $0.2(\partial F / \partial W)$. 
Regarding $\partial F / \partial W$, we can consider an average upper bound: assuming that $F=$ (number of years of service) $\times$ (number of days' wages per year of service) $\times$ (wage per day) and giving that values $F=(20)(45)(\widehat{W} / 365)$, then $F=2.4 \widehat{W}$. Thus, assuming that $\partial \widehat{W} / \partial W=1$, the average upper bound of $\partial F / \partial W=2.4$. Thus, the "positive term" is smaller than the "negative term.")

I can now examine the influence of more persistent recessions (relative to booms) on the effect of insider power on average employment. From (21),

$$
\begin{aligned}
\frac{\partial^{2} E(L)}{\partial W \partial P^{B}}= & \frac{\Pi^{B}}{c\left[\left(1-P^{G}\right)+\left(1-P^{B}\right)\right]} \\
& \times\left\{-1+\frac{\delta\left(1-P^{G}\right)}{1-\delta P^{G}}\right. \\
& \left.+(1-\delta)\left[1-\delta\left(1-P^{G}\right)\right] \frac{\partial F}{\partial W}\right\} .
\end{aligned}
$$

This expression is negative when

$$
\frac{\partial F}{\partial W}<\Psi=\frac{1}{\left(1-\delta P^{G}\right)\left[1-\delta\left(1-P^{G}\right)\right]}
$$

which holds for realistic values of the parameters. (Observe that, since $P^{G} \in[0,1]$ and considering $\delta=0.9$, the minimum value of $\Psi$ is 3.3.) Thus, the more persistent are recessions, the more contractionary is the effect of higher insider wages on employment.

\section{Conclusions}

This paper studies the influence of insider power on average labor demand when the persistence of recessions is greater than the persistence of booms and shows that, when an economy is suffering more prolonged recessions (relative to booms), a greater insider power in wage negotiations will have a more contractionary effect on average labor demand.

In a recovery, the firm will tend to hire new entrants, who are willing to accept a lower wage today if there is a probability of getting a higher insider wage in the future. In this situation, the higher insider wage does not affect the hiring decision of the firm. However, the firing decision must also be considered: employment in a recession (when the firm is firing workers) will tend to be lower, the higher is the insider wage, but also the lower is the entrant wage. Thus, the more prolonged are recessions relative to booms, the greater is the contractionary effect of insider power on employment.

This paper also takes into account the influence of the insider wage on severance payments and, in turn, its influence on employment: higher insider wages imply higher severance payments and thus less firing. This dampens the fall in employment but does not change the main conclusion of the paper.

\section{Appendix}

Revenue Function Linear Quadratic in Labour with Multiplicative Shocks and Cobb-Douglas Revenue Function. The effect of insider power on long-term employment is

$$
\frac{\partial E(L)}{\partial W}=\Pi^{G} \frac{\partial M R^{G}}{\partial W} \frac{\partial L^{G}}{\partial M R^{G}}+\Pi^{B} \frac{\partial M R^{B}}{\partial W} \frac{\partial L^{B}}{\partial M R^{B}},
$$

where $M R^{i}$ is marginal revenue. Section 3 used a revenue function linear-quadratic in labour with additive shocks $R(L, Z)=Z^{i} L^{i}-(c / 2) L^{i 2}$ and so $M R^{i}=Z^{i}-c L^{i}$. This implies that $\partial L^{G} / \partial M R^{G}=\partial L^{B} / \partial M R^{B}=-1 / c$, and thus $Z^{i}$ does not affect the relative size of the effects in booms and recession.

If the revenue function is linear quadratic in labour with multiplicative shocks $R(L, Z)=Z^{i}\left[L^{i}-(c / 2) L^{i 2}\right]$, then $M R^{i}=Z^{i}\left(1-c L^{i}\right)$. In this case, $\partial L^{G} / \partial M R^{G}=-1 / Z^{G} c$ and $\partial L^{B} / \partial M R^{B}=-1 / Z^{B} c$. Since $Z^{B}<Z^{G}$, the effect of insider power in the recession is amplified, and so all the results above hold.

For a Cobb-Douglas revenue function $R(L, Z)=$ $Z^{i}\left(L^{i(1-c)}\right) /(1-c)$ and $M R^{i}=Z^{i} L^{-c}$. In this case, $\partial L^{G} / \partial M R^{G}=$ $-\left(L^{G}\right)^{c+1} / Z^{G} c$ and $\partial L^{B} / \partial M R^{B}=-\left(L^{B}\right)^{c+1} / Z^{B} c$. The relative magnitude of $\partial L^{G} / \partial N M R^{G}$ with respect to $\partial L^{B} / \partial N M R^{B}$ depends not only on the business conditions $Z^{i}$ but also on the employment levels $L^{G}$ and $L^{B}$. I derive the levels of employment from the first-order conditions and the $M R$ :

$$
\begin{aligned}
L_{t}^{G}= & \left(\frac{b+h-\delta P^{G}\left[h-\delta\left(1-P^{G}\right) F\right]}{Z^{G}}\right)^{-1 / \beta}, \\
L_{t}^{B}=( & \left(-F+W^{B}+\delta P^{B} F-\delta\left(1-P^{B}\right)\right. \\
& \left.\times\left[h-\frac{1}{1-\delta P^{G}}\left(W^{G}-b\right)-\delta\left(1-P^{G}\right) F\right]\right)^{-1 / \beta} \\
& \left.\times Z^{B}\right)^{1 / \beta} .
\end{aligned}
$$

$L^{G}$ must be greater than $L^{B}$, which implies that

$$
\begin{aligned}
\frac{Z^{G}}{Z^{B}}> & \left(b+h-\delta P^{G}\left[h-\delta\left(1-P^{G}\right) F\right]\right) \\
\times & \left(-F+W^{B}+\delta P^{B} F-\delta\left(1-P^{B}\right)\right. \\
& \left.\times\left[h-\frac{1}{1-\delta P^{G}}\left(W^{G}-b\right)-\delta\left(1-P^{G}\right) F\right]\right)^{-1} .
\end{aligned}
$$

We know (see [13]) that the higher the $F$ and $h$ are, the more employment is stabilized over the cycle, and the closer are $L^{G}$ and $L^{B}$. Thus, when $L^{G}$ and $L^{B}$ are sufficiently close (i.e., turnover costs are sufficiently high relative to $\left(Z^{G}-Z^{B}\right)$ ), 
it may happen that $\left|\partial L^{G} / \partial M R^{G}\right|<\left|\partial L^{B} / \partial M R^{B}\right|$. This inequality is satisfied when

$$
\begin{aligned}
\frac{Z^{G}}{Z^{B}}< & \left(b+h-\delta P^{G}\left(h-\delta\left(1-P^{G}\right) F\right)\right)^{(\beta+1)} \\
\times & \left(-F+W^{B}+\delta P^{B} F-\delta\left(1-P^{B}\right)\right. \\
& \left.\times\left[h-\frac{1}{1-\delta P^{G}}\left(W^{G}-b\right)-\delta\left(1-P^{G}\right) F\right]\right)^{-(\beta+1)} .
\end{aligned}
$$

In contrast, when $L^{G}$ and $L^{B}$ are sufficiently different (turnover costs are sufficiently low), it may happen that $\left|\partial L^{G} / \partial M R^{G}\right|>\left|\partial L^{B} / \partial M R^{B}\right|$ (the inequality in (.28) must hold in the opposite direction). Thus, for sufficiently large turnover costs, the Cobb-Douglas revenue function satisfies the following condition: $\left|\partial L^{G} / \partial M R^{G}\right| \leq\left|\partial L^{B} / \partial M R^{B}\right|$. (This condition also depends on the persistence of macroeconomic fluctuations since the more prolonged is the boom, the higher is employment in a good state, and the more prolonged is the trough, the lower is employment in the bad state.) In this case, the effect of insider power in the recession is amplified, and so all the results above hold.

\section{Conflict of Interests}

The author declare that there is no conflict of interests regarding the publication of this paper.

\section{Acknowledgments}

I gratefully acknowledge financial support from the Xunta de Galicia, Spain (GPC 2013-045).

\section{References}

[1] A. Lindbeck and D. J. Snower, The Insider-Outsider Theory of Employment and Unemployment, MIT Press, Cambridge, Mass, USA, 1989.

[2] S. Bentolila, P. Cahuc, J. Dolado, and T. Le Barbanchon, "Twotier labor markets in the great recession: France versus Spain," Economic Journal, vol. 122, pp. 155-187, 2012.

[3] S. Bentolila, J. J. Dolado, and J. F. Jimeno, "Reforming an insideroutsider labor market: the Spanish experience," IZA Journal of European Labor Studies, vol. 1, article 4, 2012.

[4] G. Bertola, "Job security, employment and wages," European Economic Review, vol. 34, no. 4, pp. 851-879, 1990.

[5] E. Fehr and G. Kirchsteiger, "Insider power, wage discrimination and fairness," Economic Journal, vol. 104, pp. 571-583, 1994.

[6] J. Frank and J. M. Malcomson, "Trade unions and seniority employment rules," European Economic Review, vol. 38, no. 8, pp. 1595-1611, 1994.

[7] N. Gottfries and T. Sjöström, "Insider bargaining power, starting wages and involuntary unemployment," Scandinavian Journal of Economics, vol. 102, no. 4, pp. 669-688, 2000.

[8] E. P. Lazear, "Job security provisions and employment," Quarterly Journal of Economics, vol. 105, no. 3, pp. 699-726, 1990.
[9] A. Lindbeck and D. J. Snower, "Insiders versus outsiders," Journal of Economic Perspectives, vol. 15, no. 1, pp. 165-188, 2001.

[10] P. Díaz-Vázquez and D. J. Snower, "Can insider power affect employment?” German Economic Review, vol. 4, no. 2, pp. 139-150, 2003.

[11] P. Díaz-Vázquez and D. J. Snower, "On-the-job learning and the effects of insider power," Labour Economics, vol. 13, pp. 317-341, 2006.

[12] J. Costain, J. F. Jimeno, and C. Thomas, "Employment fluctuations in a dual labor market," Working Paper 1013, Bank of Spain, Madrid, Spain, 2010.

[13] P. Díaz-Vázquez and L. Arjona-Béjar, “The effect of turnover costs on average labour demand when recessions are more persistent than booms," ISRN Economics, vol. 2013, Article ID 138182, 13 pages, 2013.

[14] P. Díaz-Vázquez, D. J. Snower, and L. E. Arjona-Béjar, "Onthe-job learning, firing costs and employment," Contributions to Economic Analysis and Policy, vol. 4, no. 1, article 2, 2005. 

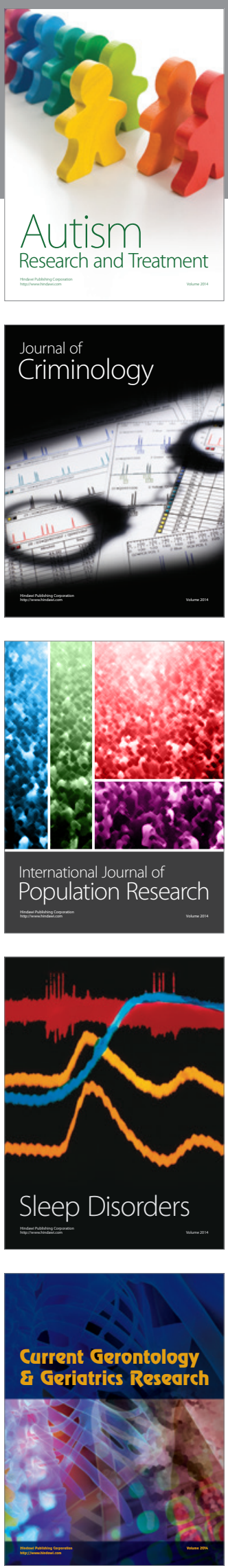
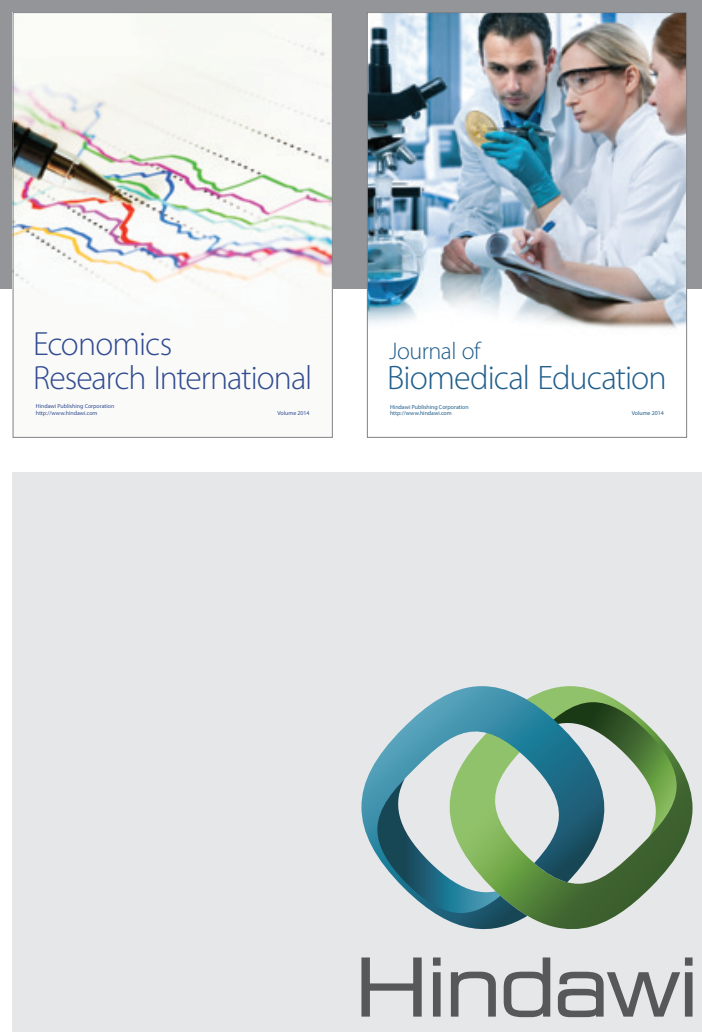

Submit your manuscripts at

http://www.hindawi.com
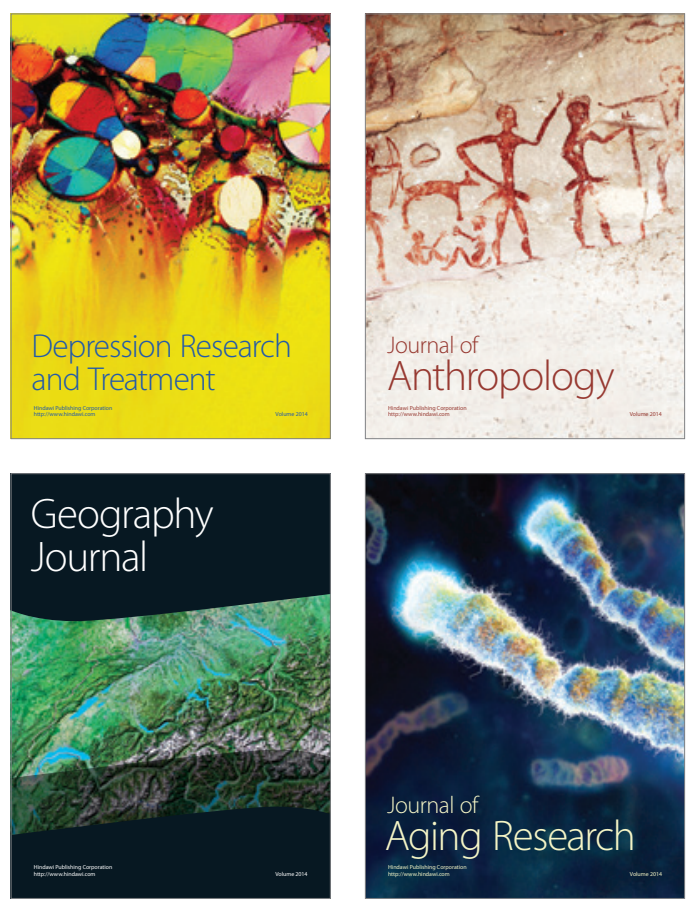
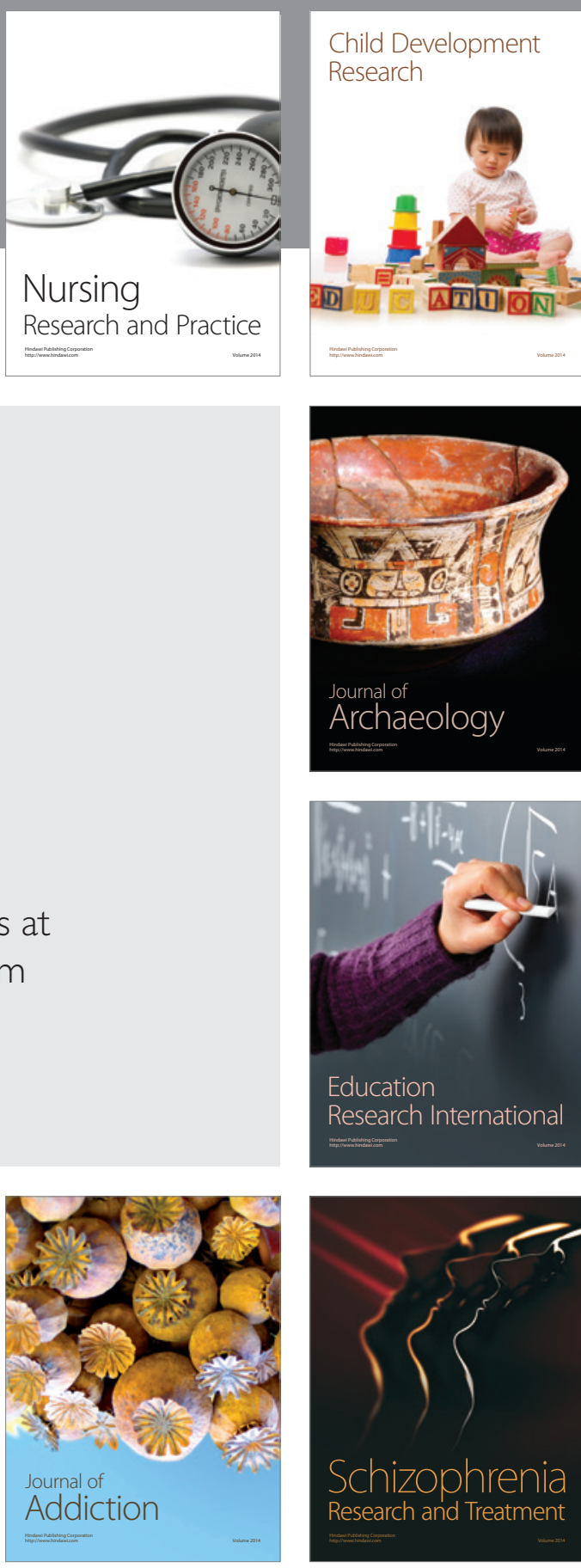

(D)
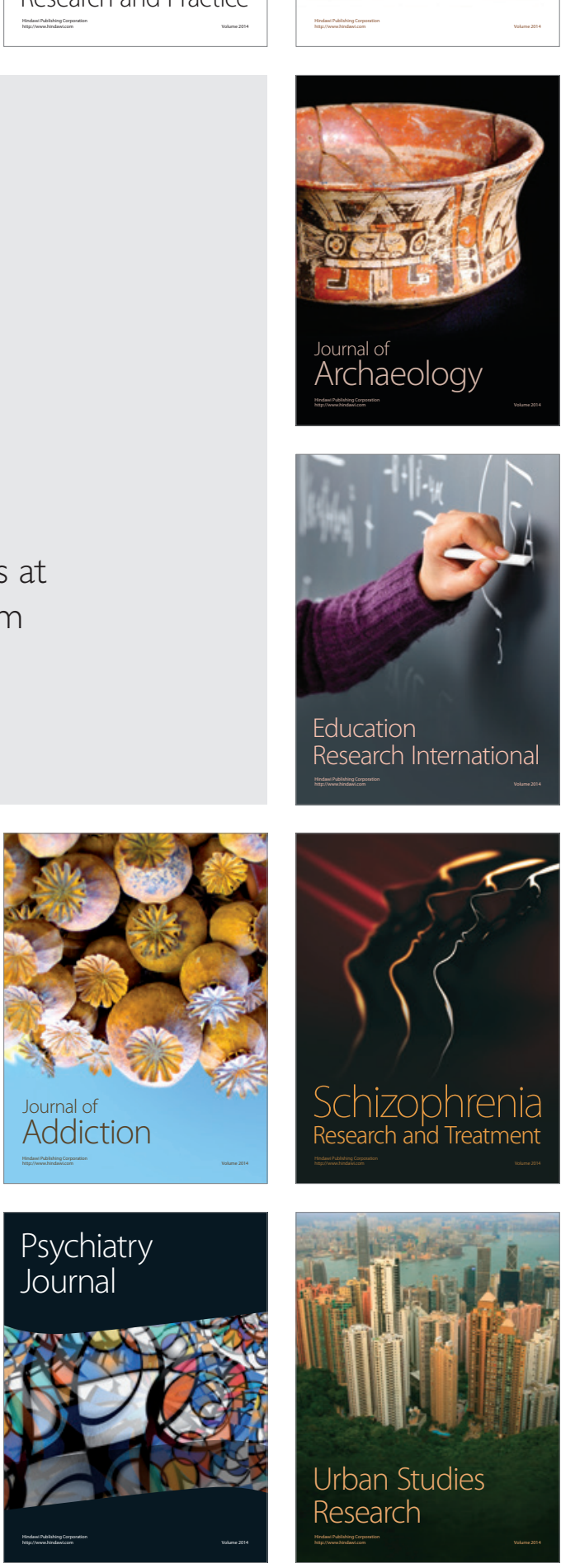